\title{
Associations between preschool attendance and developmental impairments in pre-school children in a six-year retrospective
} survey

\author{
Heribert L Stich ${ }^{\dagger 1,5}$, Bernhard T Baune* ${ }^{* 2,3}$, Riccardo N Caniato ${ }^{4}$ and \\ Alexander Krämer ${ }^{5}$
}

\begin{abstract}
Address: ${ }^{1}$ Department of Public Health, District of Dingolfing-Landau, Obere Stadt 1, 84130 Dingolfing, Germany, ${ }^{2}$ Department of Psychiatry and Psychotherapy, Mental Health Epidemiology, University of Muenster, 48149 Muenster, Germany, ${ }^{3}$ Department of Psychiatry, School of Medicine, James Cook University, Australia, ${ }^{4}$ Institute of Mental Health Services, Townsville General Hospital, Queensland, Australia and ${ }^{5}$ Department of Public Health Medicine, School of Public Health, University of Bielefeld, 33501 Bielefeld, Germany
\end{abstract}

Email: Heribert L Stich - heribert.stich@web.de; Bernhard T Baune* - bbaune@uni-muenster.de;

Riccardo N Caniato - Riccardo_Caniato@health.qld.gov.au; Alexander Krämer - alexander.kraemer@uni-bielefeld.de

* Corresponding author †Equal contributors

Published: 20 October 2006

BMC Public Health 2006, 6:260 doi: 10.1 I86/I47|-2458-6-260

This article is available from: http://www.biomedcentral.com/I47I-2458/6/260

(c) 2006 Stich et al; licensee BioMed Central Ltd.

This is an Open Access article distributed under the terms of the Creative Commons Attribution License (http://creativecommons.org/licenses/by/2.0), which permits unrestricted use, distribution, and reproduction in any medium, provided the original work is properly cited.

\begin{abstract}
Background: Many school-aged children suffer physical and mental impairments which can adversely affect their development and result in significant morbidity. A high proportion of children in western countries attend pre-school, and it is likely that the preschool environment influences the prevalence and severity of these impairments. Currently there is insufficient data available on the prevalence of these impairments and their causal associations. The influence that location of a pre-school and the duration of preschool attendance have on the prevalence of these impairments is not known.
\end{abstract}

Methods: In a retrospective survey spanning six years (1997-2002) we reviewed the records of 6,230 preschool children who had undergone routine school entry assessments. These children had been assessed utilising a modified manual of the "Bavarian Model" for school entry examinations. This model outlines specific criteria for impairments of motor, cognitive, behavioural and psychosocial functioning. Prevalence rates for physical and behavioural impairments were based on the results of these assessments. The relationship between the prevalence of impairments and the duration of preschool attendance and the location of the preschool attended was estimated utilizing logistic regression models.

Results: We found that $20.7 \%$ of children met the criteria for at least one type of impairment. Highest prevalence rates (II.5\%) were seen for speech impairments and lowest (3.5\%) for arithmetic impairments. Boys were disproportionately over represented, with $25.5 \%$ meeting the criteria for impairment, compared to $13.0 \%$ for girls. Children who had attended preschool for less than one year demonstrated higher rates of impairment (up to $19.1 \%$ for difficulties with memory, concentration or perseverance) compared to those who had attended for a longer duration (up to $11.6 \%$ for difficulties with pronouncation). Children attending preschool in an urban location had slightly elevated rates of impairment (up to $12.7 \%$ ), compared to their rural counterparts (up to II.I\%).

Conclusion: Our results demonstrate that there are high prevalence rates for physical and mental impairments among preschool children. Furthermore, children without preschool experience are a risk group for struggling with educational successes. The associations between the duration of preschool attendance and location of preschool attended and rates of impairment need replication and further exploration. Larger prospective studies are needed to examine if these relationships are causal and may therefore lend themselves to specific intervention strategies. 


\section{Background}

International literature seems to have increasingly focused on children's health issues over recent years [1-5] highlighting a growing understanding that intervention strategies that target children, are not only humane, but may be particularly effective in reducing the subsequent burden of disease in adults. A better understanding of the childhood developmental trajectories that lead to subsequent morbidity is essential for the implementation effective early intervention strategies. Evidence suggests that social and psychological factors may have as important an effect on child development as genetic, physical and cultural factors [6]. Some researchers have concluded that psychosocial factors are more important than biological ones in influencing the development of children [7].

Risk factors for poor health outcomes in children, such as lower socio-economic class, housing problems, psychological diseases of parents and poor social integration of families, have been investigated by previous authors [8]. There appears to be relatively little research, however, focused on identifying factors of attendance of a preschool associated with child development.

Results of previous studies suggests that physical and psychological disorders in children occur when risk factors outweigh protective factors during critical childhood stages, especially during the pre-school period of development $[9,10]$. Studies have shown that boys are at a significantly greater risk of developing psychological disorders during childhood than girls [11-13]. There is limited research on how specific factors, such as the preschool environment, for instance, modulate the prevalence of significant impairments. Some authors have suggested that the pre-school milieu is as important as the family environment for healthy child development [14-16]. Children learn different and essential practical skills and social competences in the pre-school setting of a preschool, which are likely to impact significantly on subsequent functioning. In this epidemiological study we investigate the effect that location of a preschool and duration of preschool attendance has on the physical, psychological and behavioural well-being of pre-school children.

\section{Methods}

We analysed all the school entry assessment records $(\mathrm{N}=$ 6,420 ) of the German district of Dingolfing-Landau for six consecutive years (1997-2002). School regulations in the province of Bavaria mandate that all children undergo a developmental assessment and a standardized physical examination before entering primary school $[17,18]$. The examinations consist of a modified version of the "Bavarian Model" for school entry examinations [19], which are carried out by a specially trained physician. These examinations assess four main developmental areas: motor, speech, cognitive and psychosocial development. Corresponding to these areas of development a standardized medical examination was carried out (Tab 1). The medical examination is manualized and standardized, and was carried out by the same qualified medical specialist over the whole study period. The medical examiner was not part of the study team and was blind to the hypotheses of the study. Social-epidemiological data for every child, such as age, gender, nationality, number of siblings, duration and location of a preschool attendance were collected from the parents.

Table I: Areas of child development and corresponding standardised tests

\begin{tabular}{|c|c|c|}
\hline main areas of development & subdivision of development & standardised tests \\
\hline \multirow[t]{2}{*}{ motor development } & gross motor skills & $\begin{array}{l}\text { standing on one leg; jumping on one leg; going like a } \\
\text { rope dancer; going with clapping hands }\end{array}$ \\
\hline & $\begin{array}{l}\text { fine motor coordination grapho- motor } \\
\text { coordination }\end{array}$ & $\begin{array}{l}\text { finger-opposition-test; drawing different figures; } \\
\text { drawing of a person }\end{array}$ \\
\hline \multirow[t]{3}{*}{ development of speech } & pronunciation & repeating words \\
\hline & grammar & $\begin{array}{l}\text { retelling a short story; retelling a short picture story; } \\
\text { explaining rules of a well known game }\end{array}$ \\
\hline & rhythm of speech & repeating sentences \\
\hline \multirow[t]{5}{*}{ development of cognition } & memory and concentration & $\begin{array}{l}\text { repeating sentences with } 7-10 \text { words including three } \\
\text { adjectives; repeating four single numbers in the } \\
\text { correct sequence }\end{array}$ \\
\hline & perseverance & $\begin{array}{l}\text { discontinuity of capacity during the whole time of } \\
\text { medical examinations }\end{array}$ \\
\hline & abstraction & $\begin{array}{l}\text { building pairs; finding out a object of various objects } \\
\text { belonging together }\end{array}$ \\
\hline & visual perception & $\begin{array}{l}\text { reception and knowing of simple geometric figures or } \\
\text { silhouettes of figures and animals }\end{array}$ \\
\hline & arithmetic & counting from I to 10 in the correct sequence \\
\hline psychosocial development & & behaviour, emotionality, psycho motor et cetera \\
\hline
\end{tabular}


Impairments of motor development were documented if the child had difficulties with two or more the standardised tests. Impairments of speech, cognition and psychosocial development were diagnosed if a child was unable to complete at least one of the standardised medical tests correctly (Tab. 1).

\section{Statistics}

Prevalence rates of impairments were stratified according to age, gender, duration of preschool attendance $(<1$ year vs. $\geq 1$ year) and location (urban vs. rural) of the preschool attended. Preschools were defined as rural in areas of less than 10,000 inhabitants and as urban where the documented population was over 10,000 . The duration of attendance at preschool was classified dichotomously as either less or more than one year in total duration. Associations between duration of attendance and location of the preschool, and developmental impairments, were calculated utilising logistical regression models, which were adjusted for age, gender and nationality. Nationality was grouped into either German or non-German. All statistics were carried out by the use of the Software package SPSS Version 12.0.

\section{Results}

Target population

During school entry examinations 6,420 children with an average age of 6.04 years $(\mathrm{SD}+/-0.37)$ were investigated. There was a slight overrepresentation of boys in the sample, with $51.7 \%(3,321 / 6,420)$ of the children being male and $48.3 \%$ female $(3,099 / 6,420)$. The average age of girls was 6.02 years $(\mathrm{SD}+/-0.37)$ and of boys it was 6.05 years (SD+/-0.36). Most of the children were German nationals (93.8\%). We obtained incomplete data sets of 190 chil- dren. Incomplete data sets resulted from unclear or ambiguous medical assessments, from changing locations and from examinations being carried out by doctors in private practices without reporting the outcomes to the Public Health Services. The final sample entered into the analysis was 6,230 children.

\section{Duration of attendance and locality of preschool}

Most of the children had attended preschool for some period $(92.9 \%)$. Children who had no documented preschool attendance $(7.1 \%$ of the sample), were not included in the analysis. Of the children who had attended preschool, $98.3 \%$ had attended for over one year while and only $1.7 \%$ had attended for less than one year. The location of the preschool attended was recorded in $99.7 \%$ of the children. Significantly more children attended preschool in rural $(73 \%)$ rather than urban (27\%) locations.

\section{Prevalence rates of impairments \\ Motor development}

Impairments of fine motor coordination (6.6\%) were more common than impairments of gross motor skills (5.9\%). Grapho-motor coordination, an assessment of the ability to draw simple figures, was impaired in $4.3 \%$ of the sample. Children younger than six years of age demonstrated higher rates of motor impairments than their older peers. Boys were almost three times as likely to demonstrate motor impairments than girls (Tab. 2). Children who visited a preschool for less than 1 year were also more likely to demonstrate deficits of motor development. No differences in motor development were seen between children having attended either rural or urban preschools (Tab. 3).

Table 2: Prevalence rates of impairments by age and gender

\begin{tabular}{|c|c|c|c|c|}
\hline \multirow[t]{2}{*}{ Impairments of development } & \multicolumn{2}{|c|}{ Age } & \multicolumn{2}{|c|}{ Gender } \\
\hline & $\begin{array}{c}\text { under } 6 \text { years } \\
\mathbf{N}=\mathbf{3 , 0 8 4} \\
\%(\mathrm{~m}=83)\end{array}$ & $\begin{array}{c}6 \text { years and older } \\
\mathbf{N}=\mathbf{3}, 1 \mathbf{4 6} \\
\%(\mathrm{~m}=109)\end{array}$ & $\begin{array}{c}\text { Girl } \\
\mathbf{N}=\mathbf{2 , 9 8 4} \\
\%(m=93)\end{array}$ & $\begin{array}{c}\text { Boy } \\
\mathbf{N}=3,246 \\
\%(m=99)\end{array}$ \\
\hline gross motor skills & 7.6 & 4.3 & 3.2 & 8.3 \\
\hline fine motor coordination & 9.0 & 4.5 & 3.2 & 9.8 \\
\hline grapho-motor coordination & 5.4 & 3.4 & 2.1 & 6.2 \\
\hline pronunciation & 11.5 & 11.3 & 7.2 & 15.1 \\
\hline grammar & 3.2 & 2.7 & 1.7 & 4.0 \\
\hline rhythm of speech & 3.5 & 3.1 & 1.9 & 4.5 \\
\hline memory and concentration & 12.3 & 5.2 & 6.4 & 10.4 \\
\hline perseverance & 8.0 & 2.6 & 4.2 & 6.0 \\
\hline abstraction & 4.9 & 2.6 & 2.4 & 4.9 \\
\hline visual perception & 6.0 & 3.9 & 2.9 & 6.7 \\
\hline arithmetic & 4.5 & 2.7 & 2.8 & 4.2 \\
\hline psychosocial development & 8.4 & 3.7 & 4.7 & 7.0 \\
\hline
\end{tabular}

$\mathrm{m}$ : missing cases 


\section{Development of speech}

Three separate areas of speech were assessed: pronunciation, grammar and rhythm of speech. Abnormalities of pronunciation were present in $11.5 \%$ of the children, while deficits in grammar $(2.9 \%)$ or rhythm $(3.3 \%)$ were far less common. Boys were over twice as likely to demonstrate deficits in speech development, than girls (Tab. 2). No significant differences in speech development were observed after stratifying for age, duration and location of a preschool attendance (Tab. 3).

\section{Development of cognition}

The most commonly observed impairments were of memory and concentration $(8.4 \%)$, while the lowest prevalence rate was found for deficits of arithmetic abilities (3.5\%). In general, we observed that boys showed twice the rate of cognitive deficits of girls. Children younger than six years of age had twice the rate of cognitive problems than their older peers (Tab. 2). Cognitive deficits were 3-4 times as prevalent in children who had attended preschool for less than 1 year. There was no difference in the rates of cognitive impairment between children attending urban or rural preschool settings (Tab. 3).

\section{Psychosocial development}

The psychosocial abilities were judged to be impaired in $5.9 \%$ of the study population. Children under six years of age were twice as likely to demonstrate psychosocial deficits than older children. Boys demonstrated higher rates of psychosocial problems $(7.0 \%)$ than girls (4.7\%). Duration of preschool attendance and location of the preschool attended did not affect psychosocial development.

\section{Associations between impairments and duration of attendance and} location of preschool

Children who had attended preschool for less than one year had significantly higher rates of impairment in most areas of psychosocial functioning. Children attending preschool for less than one year were four times as likely to demonstrate impairments of fine and gross motor skills (Tab. 4). Impairments in cognition, memory and concentration were also significantly more prevalent in children who had attended preschool for the briefer period. In the area of speech, however, the children who had attended preschool for less than one year actually demonstrated lower rates of impairment.

In all areas of development assessed, rural preschool children demonstrated lower rate of impairments than their urban counterparts (Tab. 4). The differences, however, were reasonably small and certainly not as pronounced as the differences between the children who had attended preschool for less or more than one year.

\section{Discussion}

In a retrospective survey in the Lower Bavarian district (Germany) the prevalence rates for motor, speech, cognitive and psychosocial impairments in six consecutive cohorts of school beginners were estimated. The relationship between these impairments and the duration of preschool attendance and the location of the preschool attended were assessed. Attending preschool for less than one year was a significant risk factor for several types of impairments while children attending an urban preschool had an increased risk of impairment relative to their rural counterparts. Since our data comes from a circumscribed geographical area, it may not be equally applicable to other national or international localities.

\section{Prevalence rates of impairments}

In our study about $2.8 \%$ girls and $7.3 \%$ boys demonstrated one or more motor impairments. Higher rates of impairment of motor development were seen in a previous study of school children in the district Weser-Ems [20]. In this study $6.6 \%$ of girls and $12.5 \%$ of boys demonstrated deficits of gross motor coordination and $6.2 \%$ girls and $17.6 \%$ boys had deficits of fine motor coordination. High rates of motor impairments were also found in children in Western German District of Northrhine-Westfalia [21]. In this study about 5.2\% (2.191) girls and $11.1 \%$ (5.009) boys were assessed as having of problems of motor coordination. Impairment of fine motor coordination was found in 5.6\% girls and $4.8 \%$ boys in a study of the District of Lower Saxonia (Germany) [22]. Our study, therefore, demonstrated somewhat lower rates of motor abnormalities compared to these other reports. These differences are likely to represent slight differences in school entry examinations and diagnostic procedures rather than differing prevalence rates between these populations, although the possibility of true regional differences cannot be excluded.

In the area of speech development we found that $11.5 \%$ children (6.9\% girls; $15.1 \%$ boys) demonstrated impairment in pronunciation, $2.9 \%$ (1.6\% girls, $3.9 \%$ boys) had impairments in grammar and 3.3\% (1.9\% girls; $4.4 \%$ boys) demonstrated impairments in rhythm of speech. Other reports on children's health have estimated higher rates of speech impairments than our study. A report from the district of Weser Ems for school entry children detected speech impairments in $36.2 \%$ girls and $63.8 \%$ boys [20].

To our knowledge, cognition has not been assessed in similar reviews of school entry children. The assessments utilised in our survey involved the systematic categorisation of cognitive deficits into five subgroups. We found no similar or comparable assessments documented in any previous pre-school cohorts. The large numbers of chil- 
Table 3: Prevalence rates of impairments by duration and location of the preschool

\begin{tabular}{|c|c|c|c|c|}
\hline \multirow[t]{2}{*}{ impairments } & \multicolumn{2}{|c|}{ duration } & \multicolumn{2}{|c|}{ location } \\
\hline & $\begin{array}{c}\text { under I year } \\
\begin{array}{c}\mathbf{N}=106 \\
(\mathrm{~m}=6)\end{array}\end{array}$ & $\begin{array}{c}\text { I year and longer } \\
\mathbf{N}=\mathbf{6}, \mathbf{1 2 4} \\
(\mathrm{m}=27)\end{array}$ & $\begin{array}{c}\text { Rural } \\
\mathbf{N}=4,548 \\
(m=103)\end{array}$ & $\begin{array}{c}\text { Urban } \\
\mathbf{N}=1,682 \\
(\mathrm{~m}=87)\end{array}$ \\
\hline gross motor skills & 8.5 & 5.8 & 5.0 & 8.2 \\
\hline fine motor coordination & 18.1 & 6.3 & 6.1 & 7.9 \\
\hline grapho-motor coordination & 14.9 & 4.0 & 4.1 & 4.8 \\
\hline pronunciation & 6.4 & 11.6 & 11.1 & 12.7 \\
\hline grammar & 2.1 & 2.9 & 2.3 & 4.7 \\
\hline rhythm of speech & I.I & 3.3 & 2.8 & 4.4 \\
\hline memory and concentration & 19.1 & 8.0 & 7.6 & 10.8 \\
\hline perseverance & 19.1 & 4.7 & 4.5 & 6.8 \\
\hline abstraction & 13.8 & 3.3 & 3.0 & 5.7 \\
\hline visual perception & 19.1 & 4.4 & 3.9 & 7.7 \\
\hline arithmetic & 11.7 & 3.1 & 2.7 & 5.7 \\
\hline psychosocial development & 6.4 & 5.8 & 5.4 & 7.2 \\
\hline
\end{tabular}

$\mathrm{m}$ : missing cases

dren assessed in our study and the fact that the assessments where carried out by the same medical team blind to the analysis over the study period of six years, adds to the reliability and validity to our findings. Our study indicates significant levels of cognitive impairments in the children assessed. Unfortunately, no data on cognition is available for the comparison of prevalence rates to those of other methodologies. Further studies in this field are required to obtain results for comparisons.

In our study psychosocial deficits were observed in 5.9\% children ( $4.5 \%$ girls; $6.8 \%$ boys). Lower rates of psychosocial deficits were found in a cohort of school entry children in Northrhine-Westfalia, in 1999 (2.9\% girls; 4.6\% boys) and in the following year $(3.0 \%$ for girls; $4.9 \%$ for boys) [23]. In contrast to these results, a study in Lower Saxonia detected significant behavioural deficits in 35.5\% girls and $64.5 \%$ boys [24]. It is likely that the criteria utilised to diagnose psychosocial deficits, are not sufficiently homogenous and validated to allow the comparison of prevalence rates between different studies.

\section{Associations between duration and location of preschool and children's health}

In our study, $91.7 \%$ of the children beginning school between 1997 and 2002 had visited a preschool before entering the first class of school. Of these children, 98.3\% had attended preschool more than one year and while only a small minority of children (1.7\%) had attended for less than twelve months. A general trend over time, in our study, was that the proportion of children attending preschool for less than one year declined between 1997 $(2.3 \%)$ and 1999 (0.9\%). In a survey of Lower Saxonia, children entering school had attended preschool for between 2 to 3 years in urban areas and between 1-2 years in rural areas [24]. According to a health report from the city of Mannheim only $2.3 \%$ of children had not visited a preschool before entering school [25]. All other children $(97.7 \%)$ in Mannheim had visited preschool on average for an average of 37 months [25]. In marked contrast to these figures, a survey of children in urban Cologne found only $63 \%$ of 10,086 children entering school had visited a preschool [26].

While previous public health reports on children's health have assessed the duration of preschool attendance for children entering school, they have not attempted to assess the relationship between attendance and the prevalence of developmental impairments $[22,24,25]$. We identified two other small studies which investigated the relationship between duration and location of attending a preschool and the health of pre-school children [20,28]. Similar to our study, a survey in Brandenburg, Germany, [28] reported a four-fold risk for impairments in fine and grapho-motor coordination for children who had visited preschool for less than one year. A study by BrunsPhilipps concluded that children who had never visited preschool suffered higher rates of deficits in fine motor coordination than children who had visited for longer than three years [20]. Our study also demonstrated higher rates of cognitive problems in children who had attended preschool for less than a year, however, there were no significant difference between the groups in psychosocial development. Somewhat surprisingly, for impairments of speech it was the children who had attended preschool for less than a year who had slightly lower rates of impairment.

The positive effects of attending a preschool for a longer period might be explained by various educational, psy- 
Table 4: Associations of impairments of development and time of visiting a preschool*/location of preschool*

\begin{tabular}{|c|c|c|c|c|c|c|}
\hline \multirow{2}{*}{$\begin{array}{l}\text { impairments of } \\
\text { development }\end{array}$} & \multicolumn{3}{|c|}{ visiting a preschool shorter than I year } & \multicolumn{3}{|c|}{ urban location of preschool } \\
\hline & $\begin{array}{l}\text { reference } \\
(\geq 1 \text { year) }\end{array}$ & Odds Ratio & $95 \% \mathrm{Cl}^{* *}$ & reference (rural) & Odds Ratio & $95 \% \mathrm{Cl}^{* *}$ \\
\hline gross motor skills & I & 1.47 & $0.69-3.13$ & I & 1.63 & $1.3-2.05$ \\
\hline $\begin{array}{l}\text { fine motor } \\
\text { coordination }\end{array}$ & 1 & 3.95 & $2.22-7.03$ & 1 & 1.23 & $1.01-1.60$ \\
\hline $\begin{array}{l}\text { grapho-motor } \\
\text { coordination }\end{array}$ & 1 & 4.60 & $2.45-8.5 I$ & I & 1.09 & $0.82-1.45$ \\
\hline pronunciation & I & 0.6 & $0.26-1.40$ & I & 1.2 & $1.0-1.43$ \\
\hline grammar & I & 0.78 & $0.19-3.25$ & i & 2.17 & $1.6-2.95$ \\
\hline rhythm of speech & I & 0.40 & $0.06-2.91$ & I & 1.65 & $1.23-2.23$ \\
\hline $\begin{array}{l}\text { memory and } \\
\text { concentration }\end{array}$ & 1 & 2.32 & $1.33-4.03$ & I & 1.27 & $1.04-1.55$ \\
\hline perseverance & I & 4.66 & $2.65-8.18$ & I & 1.4 & $1.09-1.79$ \\
\hline abstraction & I & 3.37 & $1.77-3.42$ & I & 1.56 & $1.2-2.1$ \\
\hline visual perception & I & 3.88 & $2.14-6.70$ & i & 1.65 & $1.28-2.12$ \\
\hline arithmetic & I & 3.13 & $1.58-6.18$ & i & 1.77 & $1.33-2.37$ \\
\hline $\begin{array}{l}\text { psychosocial } \\
\text { development }\end{array}$ & I & 1.07 & $0.46-2.50$ & I & 1.31 & $1.04-1.66$ \\
\hline
\end{tabular}

$*$ multiple logistic regression models adjusted for age, gender and nationality

*** $95 \% \mathrm{Cl}$ : $95 \%$ confidence interval

chological and social factors. In general, the preschool setting encourages children to utilise and model socially appropriate behaviour and supports the development of various skills and competencies. The socialisation process in a preschool setting may help foster healthy child development. Socially disadvantaged children are far less likely to attend a preschool [28], yet are also at higher risk of suffering from developmental impairments. Since in our study children who had never attended preschool, 7.1\% of the initial cohort, were excluded form the analysis, we may have underestimated rates of impairment. In our study only $1.7 \%$ of children had attended preschool for less than a year. Such a small sample size reduces the reliability of our findings. While our study found an association between duration of preschool attendance, we cannot be certain that this is a causal relationship due to the cross-sectional design of the study. For instance, it is conceivable that parents of more impaired children delay their entry into preschool. Shorter preschool attendance might represent a marker for an impaired state that prevents children from being enrolled. In practice, Public Health services, which are responsible for the enrollment of children in primary school and are accountable for the medical examination of all pre-school aged children, might be able to promote more accessibility of quality preschool experiences to children with social disadvantage through improving and emphasizing the recruitment process of children and parents from socially disadvantaged areas. More studies, especially those focusing on socially disadvantaged children are needed, in order to determine causative associations.
The location of a preschool seems to have a clear though less marked influence on impairments, when compared to duration of preschool attendance. Visiting a preschool in an urban region was associated with a higher risk for all the developmental deficits which we assessed. Of note is in our study rural children were significantly over represented, and that this may result in certain selection biases. To our knowledge, no previous studies have assessed the association between children's development and location of a preschool. We therefore have no other epidemiological data against which to compare our findings.

Other factors than longer duration and rural location of a preschool, so called protective factors, optimizing children's development and health are related to healthy eating, sports, social/family support and oral/dental hygiene [29]. Preventive strategies targeting at young children can be implemented at an individual, community or national level.

\section{Conclusion}

In our study we found relatively high rates of developmental impairments of pre-school children. Boys had significantly higher rates of impairment in most areas of development. These impairments might lead to significant morbidity in subsequent years, and have important implications for the planning and implementation of preventative health measures. Our findings support the conclusions that children without preschool experience are a risk group for struggling with educational successes and visiting a preschool may improve the physical, cognitive 
and psychological development of children. The observation of a cross-sectional relationship between the duration of visiting a preschool and impairment needs replication in further, including prospective studies looking at larger proportions of children not attending a preschool.

\section{Competing interests}

The author(s) declare that they have no competing interests.

\section{Authors' contributions}

HLS has made substantial contributions to conception and design, has examined the children, analyzed and interpreted data and drafted the manuscript.

BTB has made substantial contributions to conception and design, analysed and interpreted data, has been involved in drafting the manuscript and revising it critically for important intellectual content.

RNC has made substantial contributions to the writing of the manuscript.

AK has been involved in drafting the manuscript or revising it critically for important intellectual content and has given final approval of the version to be published.

All authors read and approved the final manuscript.

\section{Acknowledgements}

Special thanks to Mr. Heinrich Trapp, Landrat of the District of DingolfingLandau, Franz Beblo, MD, Chief of the local Department of Public Health and Mrs.Ursula Niederreiter for helping in making possible this study.

\section{References}

I. Bundeszentrale für gesundheitliche Aufklärung: Children's Healthepidemiological principals. Investigation and Practice of Health Promoting. Cologne 2000.

2. Robert Koch- Institute: Mean report of Federal Health Reporting. Children's and Youth's Health. Berlin 2004.

3. Elliot M, Jones JC, Jones R, Pritchard VG, Robinson BE: An interdistrict audit of the school entry medical examination in Cheshire. Public Health 1994, 108:203-210.

4. British Paediatric Association: Health services for school age children. Consulting report of the joint working party. London 1993.

5. Oberklaid F: Its time. The future of school health in Australia. Journal Paediatric Child Health 1990, 26:244-25I.

6. Hurrelmann K: Psycho- and socio-somatic deficits of health in children and Young People. Bundesgesundheitsbl-Gesundheitsforsch-Gesundheitsschutz 2002, 45:866-872.

7. Schlack HG: Socially Underprivileged Children- A Challenge for Communal Health Care. Gesundhwes 2003, 65:67I-675.

8. Esser $G$ : The meaning of organic and psychosocial risk factors to the origin of disadvantages in development. Frühford interdisz 1994, 13:49-60.

9. Karch D: Impairments of development in pre school child. Kinderarzt 1998, 19:1603-1609.

10. Jäger-Roman $E$ : Impairments of development. Supplement Abstracts Weimar "Makes School ill" 2000:18.

II. Shaywitz SE, Shaywitz BA, Fletcher JM, Escobar MD: Prevalence of reading and speeking disability in boys and girls. JAMA 1990, 264:998-1002.
12. Wohlfeil A: Impairments of development in school entering children and resulting impairments in development. Öffentl Gesundhwes 1991, 53:175-180.

13. Schulte-Körne G, Remschmidt H: Legasthenia-Symptomatics, Diagnostics, Causes, Progress and Therapy. Dt Ärztbl 2003, 100:333-338.

14. Eickhoff $\mathrm{C}$, Zinnecker J: Protect or risk. Environment of family in the mirrow of communication between parents and children. In Forschung und Praxis der Gesundheitsforderung Edited by Volume II. Bundeszentrale für Gesundheitliche Aufklärung. Köln; 2000:14-20.

15. Peisner-Feinberg ES, Clifford RM, Culkin M, Howes C, Kagan SL: The children of the cost, quality, and outcomes study go to school. Frank Porter Graham Child Development Center, NCEDL, Chapel Hill, NC; 1999.

16. Schweinhart LJ, Barnes HV, Weikart DP: Significant Benefits: The High/Scope Perry Preschool Study through Age 27. In Educational research Foundation, 10 Ypsilanti, MI: High/Scope Press; 1993.

17. Bavarian Law of Education and Instruction (BayEUG). Schulleiter ABC 200I.

18. Law of Public Health Services (Gesundheitsdienstgesetz) from July 12 1986. Gesetz- und Verordnungsblatt S. I20, BayRS 2 I 20I-A.

19. Task Force „School and Youth Health in Public Health Services". The School Entry Examination 1998.

20. Bruns-Philipps E: Data evaluation of school entry examinations (1998). Edited by: District Weser-Ems. Unpublished report; 1999.

21 . Documentation of school medicine examinations Northrhine-Westfalia. Results 2000. Landesinstitut für den Öffentlichen Gesundheitsdienst NRW; 200I.

22. Lower Saxonians Report of Children's and Youth Health Niedersächsisches Ministerium für Frauen, Arbeit und Soziales; 2000.

23. Documentation of school medicine examinations Northrhine-Westfalia. Results 1999 . Edited by Landesinstitut für den Öffentlichen Gesundheitsdienst NRW; 2000.

24. Lower Saxonians Report of Children's and Youth Health. Niedersächsisches Ministerium für Frauen, Arbeit und Soziales; 2002.

25. Schöler H, Roos J, Schäfer P, Dreßler A, Grün-Nolz PM, EnglerThümmel H: School entry examinations 2002 in Mannheim. Working report of investigating project "Differential Diagnostics". report nr.13 2002:10.

26. Mersmann H, Warrlich R: Complementary support for Children's health in social handicapped quarters by example of the city Cologne. Gesundhwes 1998, 60:638-643.

27. School Board of district Dingolfing-Landau. Personal informations about school beginners. Unpublished report

28. School beginners in Brandenburg: Social State and Health. Landesgesundheitsamt Brandenburg, I.Auflage; 1999.

29. Crall JJ: Rethinking prevention. Pediatr Dent 28(2):96-I0I. discussion 192-8.

\section{Pre-publication history}

The pre-publication history for this paper can be accessed here:

http://www.biomedcentral.com/1471-2458/6/260/pre pub 